\title{
Regimen Used to Treat Malignant Intestinal Neoplasm
}

National Cancer Institute

\section{Source}

National Cancer Institute. Regimen Used to Treat Malignant Intestinal Neoplasm. NCI

Thesaurus. Code C159893.

Any regimen that can be used for the treatment of malignant intestinal neoplasm. 